\title{
The policy on sharing data
}

\author{
Francesco Perticone ${ }^{1,2}$
}

Published online: 7 July 2016

(C) SIMI 2016

The policy on sharing data from clinical trials is taking effects, and the authors might next encounter in future the request to make individual patient data available to other researchers as a condition to publish their results [1]. The primary rationale of this policy is the need to have all clinical trial results published irrespective of outcome, and to improve public confidence in new treatments. Selective reporting and non-submission of negative results, both resulting in publication bias, threaten evidence-based medicine. The simple registration of clinical trials to existing platforms (such as http://www.clinicaltrials.gov, http://www.eudraCT.ema or similar) did not solve the issue, because only $46 \%$ of registered studies were published within 30 months of completion [2]. Most importantly, posting data in an open access environment are a powerful tool to increase transparency and validity. The availability of individual patient-level data might indeed offer the possibility to fully reanalyse trial data granting the validity of any potential findings, a quality which cannot be assured by the current peer-review process. Requiring sharing data as a condition of publication put medical journals in the position to make data sharing the norm. Some issues have to be considered.

Competition is inherent in clinical research, and unregulated implementation of a sharing data policy might allow

Francesco Perticone

perticone@unicz.it

1 President of Società Italiana di Medicina Interna, Viale dell'Università 25, 00185 Rome, Italy

2 Full Professor of Internal Medicine, Department of Medical and Surgical Sciences, University Magna Græcia, Viale Europa, 88100 Catanzaro, Italy competitors to publish contrary or misleading views. In this sense, the proposal of an invitation to co-author any publications from groups which use open access datasets may have its validity [3].

As a Scientific Society, we have to recognize that the cultural growth of new generations of researchers able to face the methodological challenges of data sharing is to be encouraged. Rather than describing them as "parasites", we have to recognize the advancement that new methods for combining and analysing new data set may offer to health promotion. Network meta-analyses are particularly vulnerable to bias, and an imbalance in effect modifiers might impair the results. Combining historical with contemporary trial, the inclusion of data obtained in minority groups and the inclusion of trials with poor internal or external validity may all make results suffering. Confidence with advanced statistical approaches is to be promoted not only to generate new evidence but also to incorporate quality into the flow of clinical care.

We also have to encourage new researchers to be ready to face methodological challenges offered by a new approach to complexity. Research in medicine is growing and technology is ready to generate big data resulting from the linkage of clinical trial data, to administrative data base, to large healthcare insurance, and to collect persongenerate health data [4]. The possibility to track their own health and fitness using wearable devices is now open to patients who may proactively contribute to online patient communities, engage with health providers, and participate in clinical research via smartphones.

\section{Compliance with ethical standards}

Conflict of interest The Author declare that he has no conflict of interest. 
Ethical approval This article does not contain any studies with human participants or animals performed by any of the authors.

Informed consent For this type of study formal consent is not required.

\section{References}

1. Taichman DB, Backus J, Baethge C, Bauchner H, de Leeuw PW, Drazen JM, Fletcher J, Frizelle FA, Groves T, Haileamlak A, James A, Laine C, Peiperl L, Pinborg A, Sahni P, Wu S (2016) Sharing clinical trial data: a proposal from the International Committee of Medical Journal Editors. Lancet 387(10016):e9-11. doi:10.1016/S0140-6736(15)01279-9
2. Ross JS, Tse T, Zarin DA, Xu H, Zhou L, Krumholz HM (2012) Publication of NIH funded trials registered in ClinicalTrials.gov: cross sectional analysis. BMJ 344:d7292. doi:10.1136/bmj.d7292

3. Flather M (2015) Open access data sharing from clinical trials: is it really feasible? Eur Heart J Qual Care Clin Outcomes 1(2):47-48

4. Antman EM, Benjamin EJ, Harrington RA, Houser SR, Peterson ED, Bauman MA, Brown N, Bufalino V, Califf RM, Creager MA, Daugherty A, Demets DL, Dennis BP, Ebadollahi S, Jessup M, Lauer MS, Lo B, MacRae CA, McConnell MV, McCray AT, Mello MM, Mueller E, Newburger JW, Okun S, Packer M, Philippakis A, Ping PP, Prasoon P, Roger VL, Singer S, Temple R, Turner MB, Vigilante K, Warner J, Wayte P (2015) Acquisition, analysis, and sharing of data in 2015 and beyond: a survey of the landscape: a conference report from the American Heart Association Data Summit 2015. J Am Heart Assoc 4(11). doi:10.1161/ JAHA. 115.002810 